\title{
Design of an Efficient Rectifier Circuit for RF Energy Harvesting System
}

\author{
Parna Kundu (Datta), Juin Acharjee and Kaushik Mandal
}

\begin{abstract}
An efficient rectifier system along with an impedance matching network is proposed in this article. Impedance matching network is designed using two microstrip lines. Rectifier system for better RF to DC conversion is designed using a bridge rectifier. The proposed rectifier system provides a maximum efficiency of 50\%. The impedance matching network improves the overall system performances significantly. The circuit simulator ADS 2015 is used for this system design. Performances of the proposed system are analysed using simulation results only. This proposed rectifier system along with the impedance matching network can be useful for the design of an efficient RF energy harvesting system.
\end{abstract}

Keywords:

Impedance matching network and rectifier circuit;

Full wave bridge rectifier;

Energy converter;

ADS-2015 circuit simulator;

GSM 900.

\section{INTRODUCTION}

E-ecently, radio frequency (RF) energy harvesting using microstrip antenna has gained a great research interest for low power applications. It consists of microwave antenna that collect ambient electromagnetic energy from the surrounding environment and a rectifier circuit which convert the collected RF energy to dc power. Since available energy can be received from any direction, an omnidirectional antenna with high gain is required to receive both horizontally and vertically polarized waves. Antenna can be designed for single band as well as multiple band reception. This basic multiband antenna with higher gain can be used in a RF energy harvesting system to collect ambient RF energy from the surrounding environment/BTS towers. An impedance matching network is essential for the efficient transmission of received power to the rectifier stage. After that the RF signals is converted in to DC using highly efficient rectifier circuits. This is illustrated using the following simplified block diagram Fig. 1.

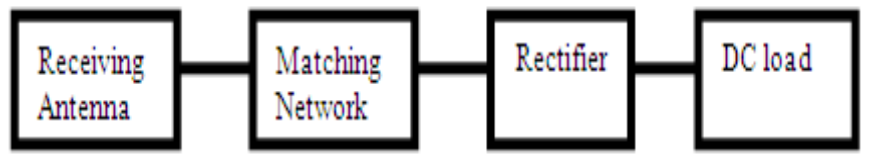

Fig. 1. Block diagram of a RF energy harvesting system.

Rectenna, short for rectifier and antenna was first designed by Brown using dipole antenna [1]. A fractal multiband antenna for energy harvesting applications [2], array with a reconfigurable dc output network for harvesting base-station power [3], optimal design of an antenna array for energy harvesting [4], and enhanced RF power harvesting [5] are reported for RF energy harvesting system design. A differential microstrip antenna [6] with improved gain for RF energy harvesting was presented by Arrawatia et al. The antenna was designed and fabricated for GSM900 band (890$960 \mathrm{MHz}$ ) with a gain of $8.5 \mathrm{dBi}$ and peak efficiency of $65.3 \%$. The same group of researcher also proposed a broad band bent triangular omnidirectional antenna [7] for RF energy harvesting. The antenna has a bandwidth of $850 \mathrm{MHz}$ to $1.94 \mathrm{GHz}$ with a peak efficiency of $60 \%$. S. Ghosh et al. proposed a circularly polarized efficient multiband microstrip antenna [8] to gather the electromagnetic energy which are radiated from the target cell towers in the GSM and CDMA bands [10]. By using a schottky diodes these energy converted in into DC power [11]. General conversion efficiency of the traditional rectenna system was $23 \%$ for frequency band of GSM 900 [12]. Rectification of the RF energy received by the antenna is very much important in the rectenna design. The efficiency of an energy harvesting system depends on RF to DC conversion efficiency of the rectifier and receiving antenna design.

This paper presents the design of an efficient impedance matching network for $2.5 \mathrm{GHz}$ and a rectifier circuit which can be used in rectenna [14] systems for higher RF to DC conversion efficiency. These circuits are designed using ADS 2015. Efficiency of the rectifier is calculated and the performance of the system is compared to understand the effect of an impedance matching network.

\section{Design of Proposed ImPEdanCe Matching NETWORK AND RECTIFIER CIRCUIT}

The antenna for the energy harvesting system is considered to be operated at $2.5 \mathrm{GHz}$ with output impedance of $50 \mathrm{ohm}$. The input impedance of the rectifier is to be matched with the output impedance of the antenna to maximize the power transfer and minimize the signal reflection from the load. A Bridge rectifier is used for RF to DC conversion. The input impedance of the bridge rectifier is calculated. Two centre taps are added to the input network and the output network to find out the input impedance of the rectifier [15]. Now if the output load $\left(R_{D}\right)$ is equally divided then there will be no current flow along the connection between the input and output centre taps. That means the alternating voltages $\mathrm{V}_{1}$ and $\mathrm{V}_{2}$ must be symmetric about a DC offset at half the output voltage.

$$
\text { If, } \mathrm{V}_{\text {in }}=\mathrm{V}_{\mathrm{p}} \sin \varphi
$$


then $V_{1}=\left(V_{m}+V_{p} \sin \varphi\right) / 2$

and $\mathrm{V}_{2}=\left(\mathrm{V}_{\mathrm{m}}-\mathrm{V}_{\mathrm{p}} \sin \varphi\right) / 2$

These two voltages are identical apart from $180^{\circ}$ phase difference and the AC component in each case is half of the input voltage. It appears that the bridge circuit splits the input voltage into two halves in antiphase. These two halves are then simultaneously applied to a pair of voltage dobler. Since there is no overall voltage multiplication
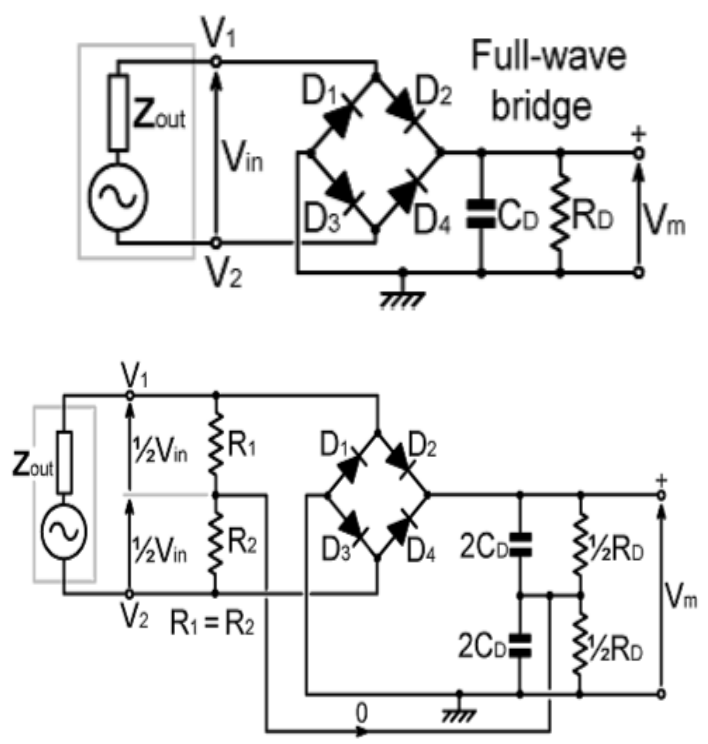

Fig. 2. General circuit diagram of the Bridge rectifier (a) Full wave bridge rectifier, (b) Full wave bridge rectifier (adding centre taps).

The input impedance is

$\mathrm{R}_{\mathrm{zin}}=\left(\mathrm{R}_{\mathrm{D}}+2 \mathrm{R}_{\text {diode }}\right) / 2$

In this paper $R_{D}$ is considered as 500 ohm and $C_{D}=0.5 p F$. A Schottky diode (HSMS8101) having cut-in voltage $0.25 \mathrm{~V}$ and dynamic resistance $9.64 \mathrm{ohm}$ is used as rectifying element in the bridge rectifier circuit. Now, from equation 2the calculated input impedance $\left(R_{\text {zin }}\right)$ of the rectifier is 259.64 ohm.

The impedance matching circuit is designed by adding two microstrip lines having $\mathrm{W}_{1}=0.257045 \mathrm{~mm}, \mathrm{~L}_{1}=15.6270 \mathrm{~mm}$, and $\mathrm{W}_{2}=0.257045 \mathrm{~mm}, \mathrm{~L}_{2}=4.944530 \mathrm{~mm}$.

\section{RESULT AND ANALYSIS}

The $S_{11}$ characteristic of the matching network is shown in Fig. 3. As per the requirement it is matched at the $2,5 \mathrm{GHz}$ to transfer maximum power from the antenna to the load.

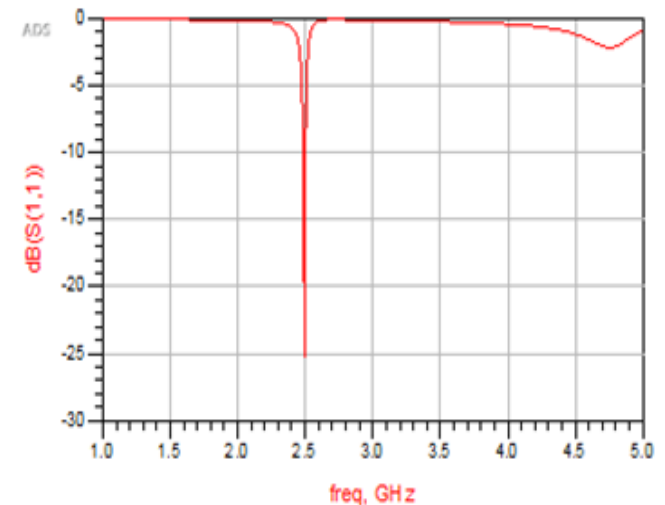

Fig. 3. Effect of Reflection Coefficient $\left(\mathrm{S}_{11}\right)$ at $2.5 \mathrm{GHz}$

Parna Kundu (Datta), Juin Acharjee and Kaushik Mandal, "Design of an Efficient Rectifier Circuit for RF Energy Harvesting System," International Journal of Advanced Engineering and Management, Vol. 2, No. 4, pp. 94-97, 2017.
Schematic circuit connectivity for the rectifier system along with the impedance matching network is presented in the Fig. 4.

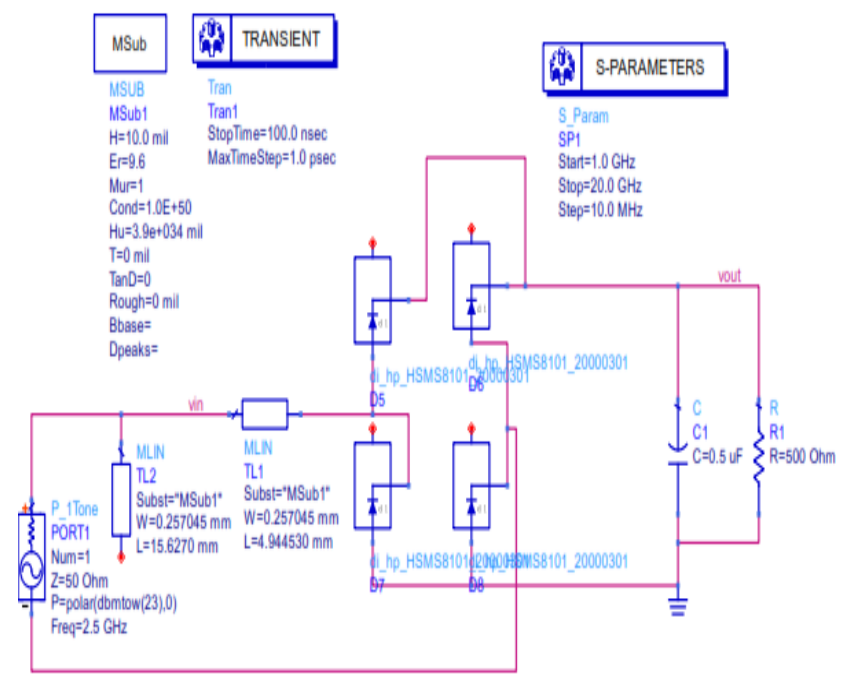

Fig.4. Schematic circuit connectivity for the rectifying system along with the impedance matching network.

\section{Calculation of Rectifier Efficiency}

The antenna is directly connected with the simply bridge rectifier circuit with impedance matching. The efficiency of the RF to DC conversion is defined as the ratio of the output dc power $\left(\mathrm{P}_{\text {out }}\right)$ and input $\mathrm{RF}$ power $\left(\mathrm{P}_{\text {in }}\right)$.

The efficiency of the rectifier $(\eta)$ can be calculated by

$\eta=\frac{P_{\text {out }}}{P_{\text {in }}}$

Where, $\quad \mathrm{P}_{\text {out }}=\mathrm{V}^{2}$ out,DC $/ \mathrm{R}_{\text {load }}$

$\mathrm{V}_{\text {out }}=$ Output DC Voltage

$\mathrm{R}_{\text {load }}=$ Resistive load present at the output

Efficiency of the rectifier is calculated for different input power and presented in the Table 1.

Table 1. Calculated Efficiency of the Bridge Rectifier

\begin{tabular}{|c|c|c|c|}
\hline $\begin{array}{c}\text { Input } \\
\text { Power(dBm) }\end{array}$ & $\begin{array}{c}\text { Input } \\
\text { Power(mWatt) }\end{array}$ & $\mathbf{V}_{\text {out }}($ Volt) & $\begin{array}{l}\text { Rectifier } \\
\text { Efficiency } \\
(\%)\end{array}$ \\
\hline 0 & 1 & 0.131 & 3.43 \\
\hline 5 & 3.16 & 0.502 & 15.94 \\
\hline 7 & 5.012 & 0.742 & 21.96 \\
\hline 10 & 10 & 1.23 & 30.26 \\
\hline 12 & 15.84 & 1.68 & 35.63 \\
\hline 15 & 31.62 & 2.58 & 42.10 \\
\hline 17 & 50.12 & 3.39 & 45.86 \\
\hline 20 & 100 & 5.01 & 50.20 \\
\hline 23 & 199.52 & 6.94 & 48.28 \\
\hline
\end{tabular}

The rectifier along with impedance matching network is highly efficient with maximum efficiency of $50.20 \%$ for the $20 \mathrm{dBm}$ input power. The proposed rectifier system is able to produce sufficient DC voltage form low incident RF power. This simple rectifier system is very efficient for design of a RF energy harvesting system. The input power versus efficiency variation is shown in Fig. 5. 


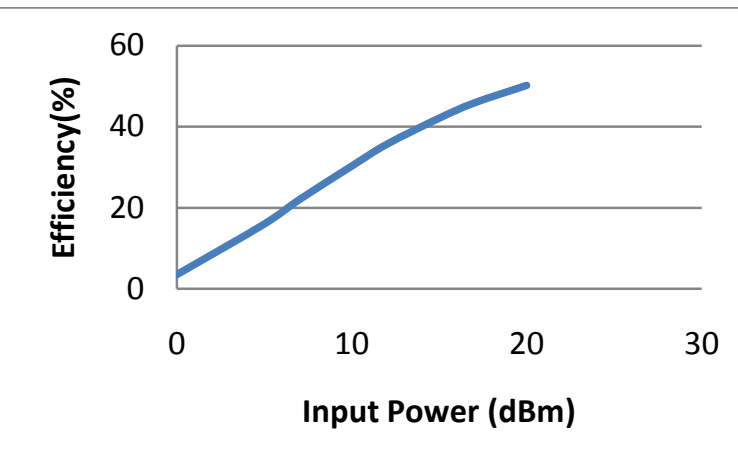

Fig.5. Efficiency of the bridge rectifier for different input power

A comparative study of the rectifier performance, with and without impedance matching network is shown in Fig.6. It is observed that due to impedance matching the efficiency of RF to DC conversion is so high.

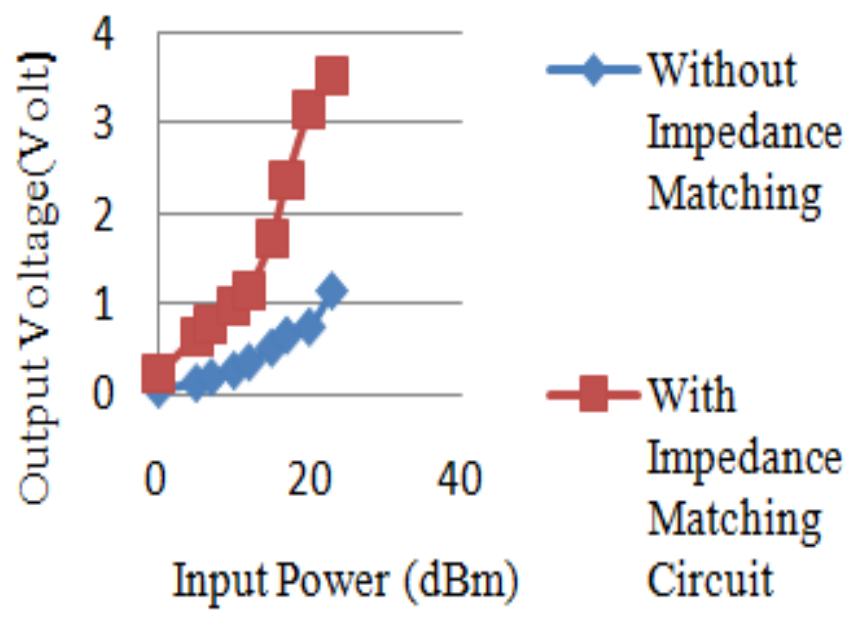

Fig.6. Output voltage versus input power.

\section{CONCLUSION}

An efficient rectifier system for RF energy harvesting system is designed using ADS-2015 circuit simulator. It consists of an impedance matching network $\mathrm{t}$ and a bridge rectifier. Schottky diode is used as a rectifying element as it has low forward voltage drop and a very fast switching speed. Impedance matching network effectively improves the system performance. This system is found suitable for a part of RF energy harvesting system.

\section{References}

[1] Xie, F., Yang, G. M., \& Geyi, W. (2013). Optimal design of an antenna array for energy harvesting. IEEE Antennas and Wireless Propagation Letters, 12, 155-158.

[2] Claps, R., Englich, F. V., Leleux, D. P., Richter, D., Tittel, F. K., \& Curl, R. F. (2001). Ammonia detection by use of near-infrared diode-laser-based overtone spectroscopy. Applied Optics, 40(24), 4387-4394.

[3] Visser, H. J., \& Vullers, R. J. (2013). RF energy harvesting and transport for wireless sensor network applications: Principles and requirements. Proceedings of the IEEE, 101(6), 1410-1423.

[4] Arrawatia, M., Baghini, M. S., \& Kumar, G. (2016). Broadband bent triangular omnidirectional antenna for RF energy harvesting. IEEE Antennas and Wireless Propagation Letters, 15, 36-39.

[5] Taghadosi, M., Albasha, L., Qaddoumi, N., \& Ali, M. (2015). Miniaturised printed elliptical nested fractal multiband antenna for energy harvesting applications. IET Microwaves, Antennas \& Propagation, 9(10), 1045-1053.

[6] Ghosh, S., \& Chakrabarty, A. (2016, January). Green energy harvesting from ambient RF radiation. In Microelectronics, Computing and Communications (MicroCom), 2016 International Conference on (pp. 1-4). IEEE.

[7] Olgun, U., Chen, C. C., \& Volakis, J. L. (2011). Investigation of rectenna array configurations for enhanced RF power harvesting. IEEE Antennas and Wireless Propagation Letters, 10, 262-265.

[8] Brown, W. C. (1984). The history of power transmission by radio waves. IEEE Transactions on Microwave Theory and Techniques, 32(9), 1230-1242.

[9] Reddy, N. K., Hazra, A. \& Sukhadeve, V. R. (2017). A Compact Elliptical Microstrip Patch Antenna for Future 5G Mobile Wireless Communication. Transactions on Engineering and Applied Sciences, 1(1), 1-4.

[10]Acharjee, J., Kumar, R. L., Mandal, K., Mandal, S. K. (2017). Design of Matched Printed Monopole Antenna with Enhanced Bandwidth for GSM900 Band Application. Transactions on Engineering and Applied Sciences, 1(1), 5-8.

[11] Karthaus, U., \& Fischer, M. (2003). Fully integrated passive UHF RFID transponder IC with $16.7-/ \mathrm{spl} \mathrm{mu/W}$ minimum RF input power. IEEE Journal of Solid-State Circuits, 38(10), 1602-1608.

[12] Costanzo, A., Romani, A., Masotti, D., Arbizzani, N., \& Rizzoli, V. (2012). RF/baseband co-design of switching receivers for multiband microwave energy harvesting. Sensors and Actuators A: Physical, 179, 158168.

[13] Rizzoli, V., Costanzo, A., Masotti, D., \& Donzelli, F. (2010). Integration of numerical and field-theoretical techniques in the design of single-and multi-band rectennas for micro-power generation. International Journal of Microwave and Wireless Technologies, 2(3-4), 293-303.

[14] McSpadden, J. O., Fan, L., \& Chang, K. (1998). Design and experiments of a high-conversion-efficiency $5.8-\mathrm{GHz}$ rectenna. IEEE Transactions on Microwave Theory and Techniques, 46(12), 2053-2060.

[15] Popovic, Z., Korhummel, S., Dunbar, S., Scheeler, R., Dolgov, A., Zane, R., \& Hagerty, J. (2014). Scalable RF energy harvesting. IEEE Transactions on Microwave Theory and Techniques, 62(4), 1046-1056.

Authors Details:

Parna Kundu (Datta)

ECE, NSHM Knowledge Campus ,Durgapur

e-mail:Parna.kundu@nshm.com

Parna Kundu (Datta), Juin Acharjee and Kaushik Mandal, "Design of an Efficient Rectifier Circuit for RF Energy Harvesting System," International Journal of Advanced Engineering and Management, Vol. 2, No. 4, pp. 94-97, 2017. 
Juin Acharjee

ECE, NSHM Knowledge Campus ,Durgapur

e-mail: Juin.Acharjee@nshm.com

Kaushik Mandal

Institute of Radio Physics \& Electronics,Calcutta University,

Kolkata

e-mail: kaushikrpe@gmail.com 